\title{
Response of 50-year Regional Climatic Variation to Global Warming in the Desert Area of Northwestern China
}

\author{
Shujuan Zhu ${ }^{1,2,3}$, Zhaofeng Chang ${ }^{1,2,3}$ \& Caizhou Kang ${ }^{1,2,3}$ \\ ${ }^{1}$ Gansu Minqin National Field Observation \& Research Station on Ecosystem of Desertified Rangeland, Minqin, \\ Gansu, China \\ ${ }^{2}$ Key Laboratory of Desertification Combating of Gansu Province, Lanzhou, Gansu, China \\ ${ }^{3}$ Gansu Desert Control Research Institute, Lanzhou, Gansu, China \\ Correspondence: Zhaofeng Chang, Gansu Minqin National Field Observation \& Research Station on Ecosystem \\ of Desertified Rangeland, Minqin, Gansu 733300, China. Tel: 86-931-768-6191. E-mail: czf123@sina.com
}

Received: June 27, 2012 Accepted: July 16, 2012 Online Published: August 10, 2012

doi:10.5539/jgg.v4n3p69 URL: http://dx.doi.org/10.5539/jgg.v4n3p69

\begin{abstract}
The climate in desert is totally different from those in other landscapes. This paper, by analyzing the data collected in Minqin desert area during the period of 1961-2009, attempts to figure out how the temperature, precipitation and air humidity in the desert area of northwestern China respond to global warming. The result revealed that: the increasing rate of the mean annual temperature in Minqin during 1961-2009 was greater than that of the global average and that of the hundred-year average in China; whereas lower than that in the arid area in northeastern China in the recent 20 years. In Minqin, the temperatures in winter and spring rose significantly. The winter and spring temperatures and the annual maximum temperature showed big variations, with great fluctuations. The annual air humidity increased dramatically while the precipitation displayed an insignificant increasing trend. There was a significant correlation between air humidity rising and precipitation increasing. However, there's no sound consistency between the periodic variations of air humidity and those of precipitation. The warmer spring usually induced intensive sandstorms, and the instability of air temperatures has caused yield reduction of crops/ fruits in the study area.
\end{abstract}

Keywords: air temperature, precipitation, response to global warming, desert area in northwestern China

\section{Introduction}

Global warming is now a hot topic worldwide. The $3^{\text {rd }}$ evaluation report by IPCC (Intergovernmental Panel on Climate Change) indicated that the world's average temperature in the $20^{\text {th }}$ centaury rose by $0.6 \pm 0.2^{\circ} \mathrm{C}$, with the warmest period appearing in 1980s and 1990s (Houghton et al., 2001). The $4^{\text {th }}$ evaluation report by IPCC showed that from 1906 to 2005 , the average air temperature in the world rose by $0.74^{\circ} \mathrm{C}$, and the average temperature in the latter half of the $20^{\text {th }}$ century was the highest in the last 1300 years (IPCC, 2007). According to a model manipulation, "the most possible scenario" of temperature rising globally will be $1.8-4^{\circ} \mathrm{C}$ by 2100 , and the sea level will rise by $18-59 \mathrm{~cm}$. Provided that the temperature rises by $1.5-2.5^{\circ} \mathrm{C}$ in the coming years (in contrast to that during 1980-1999), 20\%-30\% of the species will probably go extinct and the percentage will reach $40 \%-70 \%$ if the temperature rises by $3.5^{\circ} \mathrm{C}$ (Qin et al., 2007). The latest report drafted by UNIPCC's work team indicates that from 1860 to the present, the temperature in the northern hemisphere has risen by $0.4-0.8^{\circ} \mathrm{C}$ averagely. The temperature rose more dramatically in the 20th century than at any other time in the millennium and the average temperature from1990 to 1999 was the highest in the millennium (Mann et al., 1999; Qin et al., 2002). Global warming during the $20^{\text {th }}$ centaury draws more and more attention in recent years.

Global warming will induce precipitation increase. The simulation experiments showed that the average global precipitation would increase by $115 \%-310 \%$ provided the temperature rises by $1^{\circ} \mathrm{C}$ (IPCC, 1990; Hulme et al., 1998). Hulme (1996) analyzed the data collected from 1900 to 1994 and revealed that correlation coefficient between the average precipitation and the temperature was 0.36 at the inter-annual scale, and 0.51 at the inter-decadal scale, with the significance of both of them exceeding $99.9 \%$. Due to extremely high temperature, the pollen hypersensitivity in the middle- to high-latitudinal areas in the northern hemisphere advanced, and the population mortality in some European areas also increased (IPCC, 2007; Sun et al., 2002). 
In the $20^{\text {th }}$ century, the temperature in China has risen by $0.4-0.5^{\circ} \mathrm{C}$, slightly lower than world's average, $0.6^{\circ} \mathrm{C}$. In Shanxi, Gansu, Ningxia and Xinjiang provinces in northwest China, the temperature rising extent is greater than China's average (Qin et al., 2002; Wang \& Dong, 2002; Ding, 2002). Northeastern China is one of the regions with sensitivity response to global warming. Its average temperature from 1981 to 1999 rose by $1{ }^{\circ} \mathrm{C}$, in contrast to the average from 1951 to 1980 . In recent 50 years, the temperatures in the southern part of northeast China and in most parts of North China rose by $0.5-1.0^{\circ} \mathrm{C}$ (Sha et al., 2002). The average temperature in northern Xinjiang in recent 10 years was $0.7^{\circ} \mathrm{C}$ higher, and that in Tianshan Mountain ranges was $0.4^{\circ} \mathrm{C}$ higher than the average in the past 30 years, respectively (Ding, 2002). The average annual temperatures in Shanxi, Gansu and Ningxia provinces in the past 50 years also displayed a rising trend, with more intensive increasing in winter and spring, and the precipitation showed a decreasing trend in the same period (Ding \& Yan, 2007). The apparent large-scale precipitation increasing mainly occurred in the western China, especially in northwestern China (Zhai et al., 2005). Kitoh et al. (1997) found that rainfall brought by summer monsoon from the Indian Ocean increased apparently with global warming. The study by Chinese scholars indicated that the increasing or decreasing of rainfalls in the arid areas in northwest China were, to some extent, related to the global temperature rising/dropping (Leng et al., 2007; Jin et al., 2005).

The responses of temperature rising to global warming differentiate in various regions with different land forms (Ding, 2002). Desert is one of the three natural landscapes on the continent. The eco-environmental phenomena in arid and semi-arid areas are closely related to temperature rising (Hu et al., 2001). The climate in the desert area is quite different from that in other regions (Chang \& Zhao, 2006). However, few studies on the response of desert climate to global warming and on the stability of temperature changes are available. This study was conducted in Minqin desert area in northwest China. It analyzed the responses of climatic changes in desert area to global warming as well as the stability of climate changes.

\section{Study Site}

Minqin county $\left(102^{\circ} 03^{\prime}-104^{\circ} 03^{\prime} \mathrm{E}, 38^{\circ} 05^{\prime}-39^{\circ} 06^{\prime} \mathrm{N}\right)$ is located in the lower reaches of the Shiyang River in the northeastern Hexi corridor in Gansu province, and at the western fringe of Tengger Desert in China (Figure 1). It has an area of $16016 \mathrm{~km}^{2}$ and an average elevation of $1300-1350 \mathrm{~m}$, the average annual precipitation is $116.52 \mathrm{~mm}$, while the evaporation is $2351.79 \mathrm{~mm}$. The landscape in Minqin can be classified into three types: the natural landscapes formed before Han dynasty (2100 years ago), the degraded lands from Han dynasty to Minguo Age (from BC 206 to AD 25), and the artificial lands reclaimed since 1949.

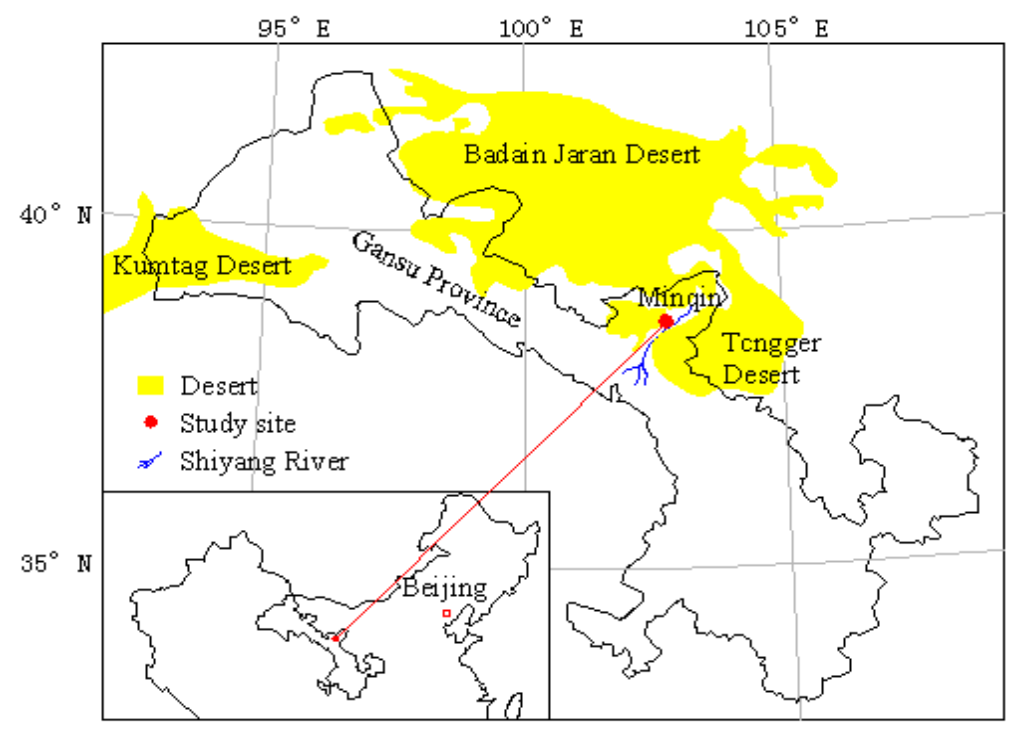

Figure 1. Location of the study site

The study site is a typical desert in China. Desert, Gobi, alkali-saline land, low hills and sand dunes currently occupy $94.2 \%$ of the total area. Among which, desert is $8813.3 \mathrm{~km}^{2}(55.03 \%)$, Gobi is $800.0 \mathrm{~km}^{2}(5.00 \%)$ and desertified rangeland is $5466.67 \mathrm{~km}^{2}(34.13 \%)$. Total population is 307,200 with a density of 19.18 persons $/ \mathrm{km}^{2}$. 
Currently, the eco-environment in Minqin is degrading mainly in three ways. 1) Rapid dropping of underground water. At present, water table inside and around Minqin oasis has dropped to around $20 \mathrm{~m}$ due to overuse of water resources through boreholes since 1950s. $2 \times 10^{4} \mathrm{~km}^{2}$ farmland in the lower reaches of the Shiyang River has been abandoned since 1950s because of water shortage. The land was desertified once abandoned, and the farmland is continuously shrinking. 2) Vegetation degradation induced by the death of plants. Large area of sand-fixation plants were planted in Minqin in 1960s and 1970s, however, they are decaying now. $5800 \mathrm{~km}^{2}$ of artificial Eleagnus angustifolia are dying and $300 \mathrm{~km}^{2}$ of them were already dead, whereas $60 \%$ of the 44600 $\mathrm{km}^{2}$ artificial Haloxylon ammondendron are degrading. There are now $73300 \mathrm{~km}^{2}$ of natural Nitraria tangutorum in the area, among which, $67.7 \%$ with the coverage $<30 \%, 17.5 \%$ with the coverage $<10 \%$. At the beginning of 1980 s, there once was $372.6 \mathrm{~km}^{2}$ of Populus euphratica in Minqin, but they disappeared now. The desertified rangeland in Minqin is also degrading at a large scale. 3) Strong winds and sandstorms occurred more frequently than ever. The observational data provided by Minqin Desert Control Experimental Station showed that since $1970 \mathrm{~s}$, there have been annually 28.2 days with $\geq 17 \mathrm{~m} \cdot \mathrm{s}^{-1}$ gales, $25.8 \mathrm{~d}$ with sandstorm, $37.8 \mathrm{~d}$ with sand-driven winds, and $30.2 \mathrm{~d}$ with dust.

\section{Material and Methods}

\subsection{Material}

Meteorological data collected from the Minqin Desert Control Experimental Station during 1961-2009 were used. Sunshine duration, air temperature, air pressure, rainfall, humidity, ground temperature, wind speed and wind direction, days of gales and sandstorms were observed. In each observational item, several indicators were included. For instance, in item of air temperature, monthly and annual average temperatures, the monthly maximum and minimum temperatures were included; in item of rainfall, monthly and annual rainfall and the diurnal rainfall intensity were considered.

\subsection{Methods}

Linear regression was used to express the variation trends of average temperature, the maximum $/ \mathrm{minimum}$ temperatures, precipitation and air humidity, and the regression significance was tested with $95 \%$ confidence level. The variation trend of the variants was denoted by the absolute values of the difference between the two adjacent values. In the figures, the variation trend of the variants was denoted by the angle formed by the lines above and below the general trend line. The correlation among variants was denoted with Pearson coefficient, and the relative significance was tested with 2-tailed method. All the data were analyzed with SPSS13.0 software.

\section{Results}

During 1961-2009, the mean annual temperature showed a significant rising trend $(p<0.05)$, with the rising rate of $0.110^{\circ} \mathrm{C} \cdot(10 \mathrm{a})^{-1}$ (Figure 2a). The annual mean precipitation during 1961-2009 displayed an insignificant increasing trend $(P>0.05)$ (Figure $2 \mathrm{~b})$, with the increasing rate of $3.97 \mathrm{~mm} \cdot(10 \mathrm{a})^{-1}$. The air humidity during 1961-2009 showed a significant increasing trend $(P<0.01)$, with the increasing rate of $1.87 \% \cdot(10 \mathrm{a})^{-1}$ (Figure $2 \mathrm{c}$ ). During 1988-2009, sandstorm incidence significantly decreased $(P<0.01)$ (Figure 2d), with the decreasing rate of $2.45 \mathrm{~d} \cdot(10 \mathrm{a})^{-1}$.

\subsection{Temperature Variation}

\subsubsection{Periodic Variation of the Mean Annual Temperature}

The annual average temperature during 1961-2009 showed an insignificant rising trend ( $\mathrm{P}>0.05)$ (Figure 3a). The 5-year running average of the mean annual temperature showed that the running temperature from 1961 to 2009 experienced seven stages: a decreasing trend during 1961-1971, an increasing trend during 1971-1975, a decreasing trend during 1975-1985, an increasing trend during 1985-1991, a decreasing trend during 1991-1996, an increasing trend during 1996 -2002, and a decreasing trend during 2002-2009 (Figure 3b).

\subsubsection{Variation of Monthly Average Temperature}

During 1961-2009, the temperatures in February, April, December, March, May and June displayed an increasing trend (Figure 3c), with significant increasing in February and April $(\mathrm{P}<0.05)$, and insignificant increasing or decreasing in the remaining months $(\mathrm{P}>0.05)$. The temperatures in August and September displayed an insignificant decreasing trend $(\mathrm{P}>0.05)$ (Table 1). 
$\mathbf{a}$

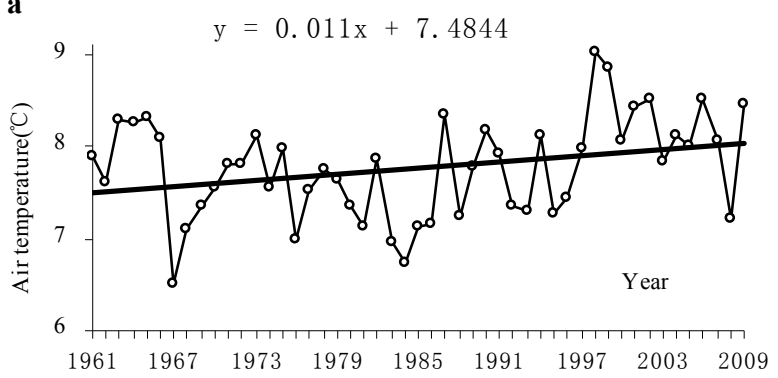

c

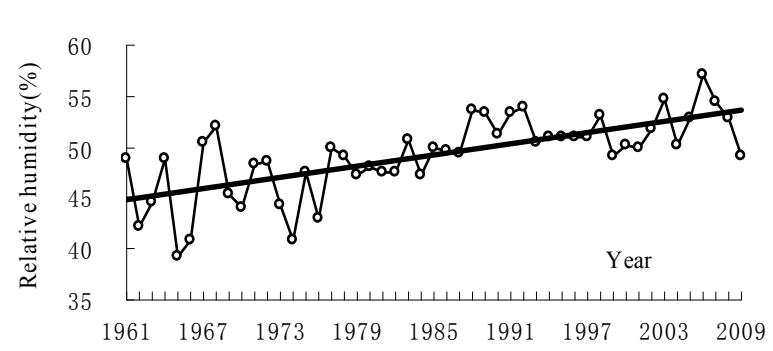

b

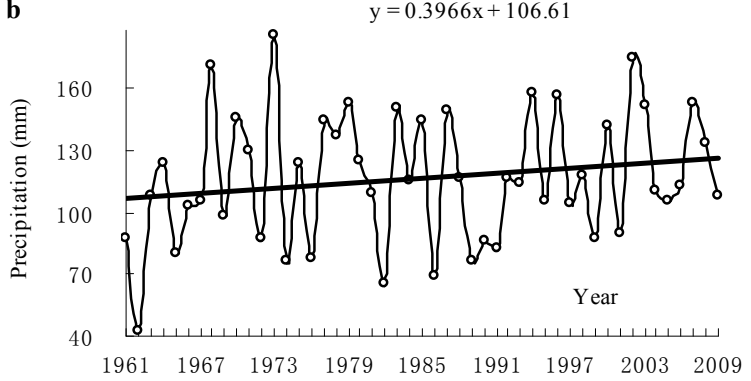

d

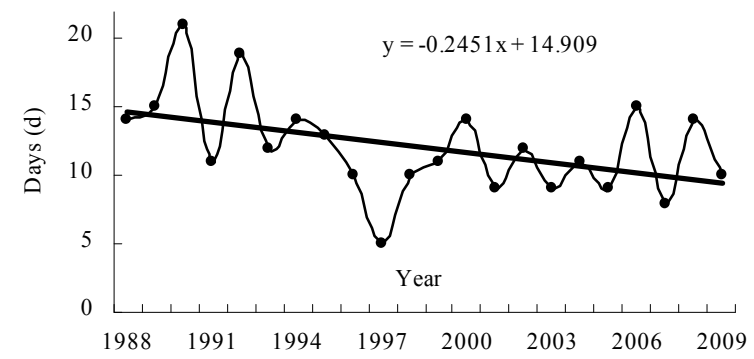

Figure 2. a) Mean annual temperature during 1961-2009; b) Annual average precipitation during 1961-2009; c)

Annual air humidity during 1961-2009; d) Decreasing trend of sandstorm incidence during 1988- 2009
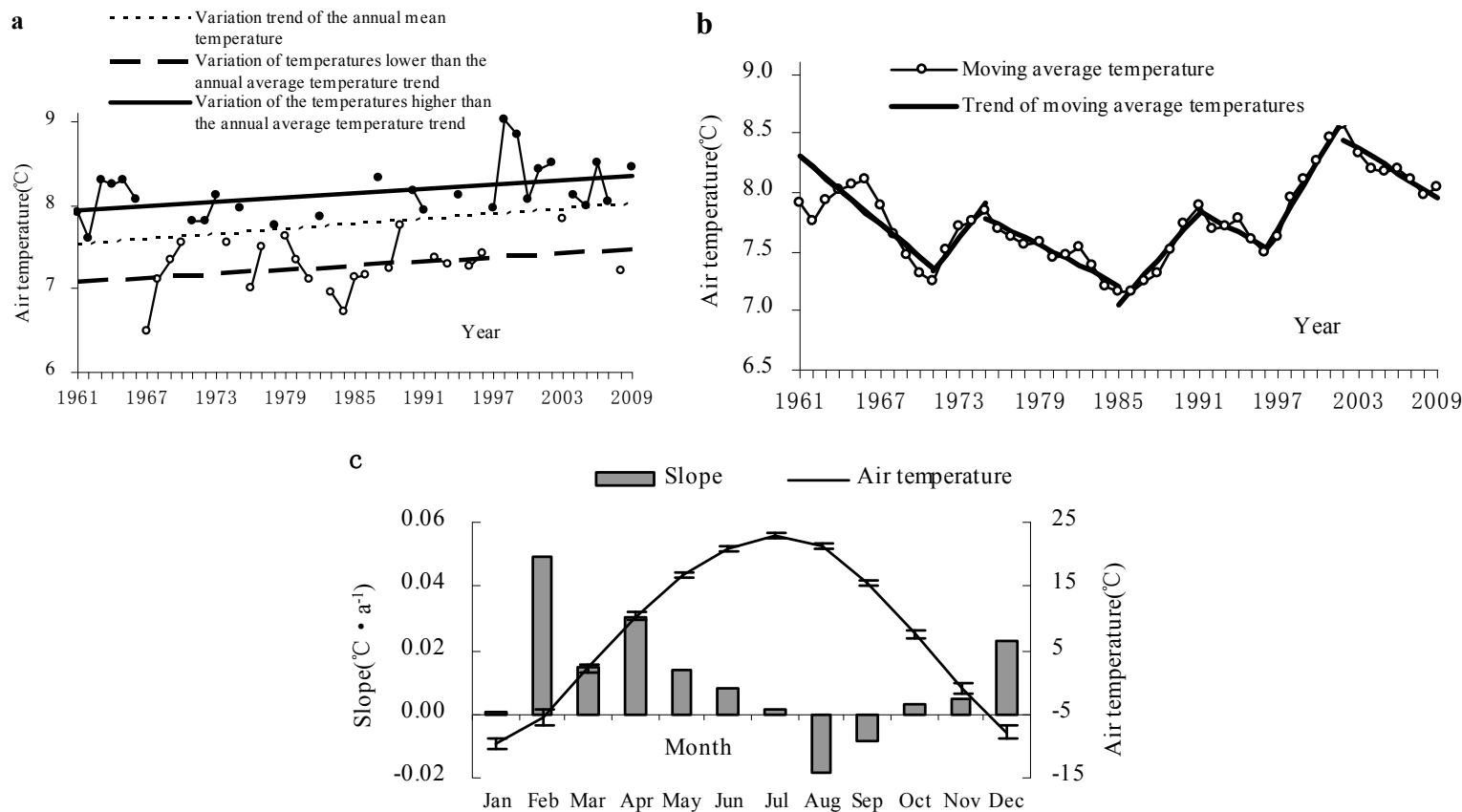

Figure 3. a) Variation of the annual mean temperatures during 1961-2009; b) Running average of the annual mean temperatures during 1961-2009; c) Variation of the monthly average temperatures during 1961-2009

The correlation of temperature variations between May and whole the year was insignificant $(\alpha>0.05)$, while that between July/October and whole the year was comparatively significant $(\alpha<0.05)$. The correlation between the remaining months and whole the year was significant $(\alpha<0.01)$, in which, the correlation coefficients in February, August, March, January, November and April were the highest (Table 1). The correlation between the monthly and annual temperature variations showed the monthly average temperature was closely related to the mean annual temperature. The standard difference of the temperature variation showed that the temperature variation 
in February was the least stable, followed by that in December, January, November, April and March, and that in June being the most stable (Table 1).

Table 1. Trend line slope of annual average temperature and the yearly variance proportion during 1961-2009

\begin{tabular}{|c|c|c|c|c|c|c|c|c|c|c|c|c|}
\hline Month & Jan. & Feb. & March & April & May & June & July & Aug. & Sep. & Oct. & Nov. & Dec. \\
\hline Trend line slope $\left({ }^{\circ} \mathrm{C} \cdot \mathrm{a}^{-1}\right)$ & 0.001 & $0.049 \#$ & 0.015 & $0.030 \#$ & 0.013 & 0.008 & 0.001 & -0.019 & -0.009 & 0.003 & 0.005 & 0.023 \\
\hline Relative coefficient (r) & $0.485^{* *}$ & $0.491^{* *}$ & $0.488^{* *}$ & $0.441 * *$ & 0.035 & $0.369^{* *}$ & $0.294 *$ & $0.491 * *$ & $0.390^{* *}$ & $0.350^{*}$ & $0.456^{* *}$ & $0.385^{* *}$ \\
\hline Standard variation & 1.751 & 2.397 & 1.355 & 1.387 & 0.967 & 0.762 & 0.825 & 0.964 & 1.013 & 1.125 & 1.538 & 2.009 \\
\hline
\end{tabular}

Note: \# denotes the regression is significant at the confidence level of $95 \%(\mathrm{p}<0.01) ; * *$ denotes the relative coefficient is significant at the level of $\alpha<0.01 ; *$ denotes the relative coefficient is significant at the level of $\alpha<0.05$

\subsubsection{Maximum Temperature}

During 1961-2009, the annual maximum temperature in Minqin was $37.16^{\circ} \mathrm{C}$ in average, with the peak in 1997 (July $22 \mathrm{nd}), 41.0^{\circ} \mathrm{C}$. It showed an insignificant rising trend $(\mathrm{P}>0.05)$ (Figure $\left.4 \mathrm{a}\right)$, with the rising rate of $0.10^{\circ} \mathrm{C} \cdot(10 \mathrm{a})^{-1}$. The inter-annual difference of the maximum temperature from 1961 to 2009 displayed a significant increasing trend $(\mathrm{P}<0.05)$, with the rate of $0.261^{\circ} \mathrm{C} \cdot(10 \mathrm{a})^{-1}$ (Figure $\left.4 \mathrm{~b}\right)$. In Figure $4 \mathrm{~b}$, the values on the line above the general trend line display a significant rising trend $(\mathrm{P}<0.05)$, with the rising rate of $0.37^{\circ} \mathrm{C} \cdot(10 \mathrm{a})^{-1}$; whereas those on the line below the general trend line display an insignificant decreasing trend $(\mathrm{P}>0.05)$ (Figure $4 b)$.

a

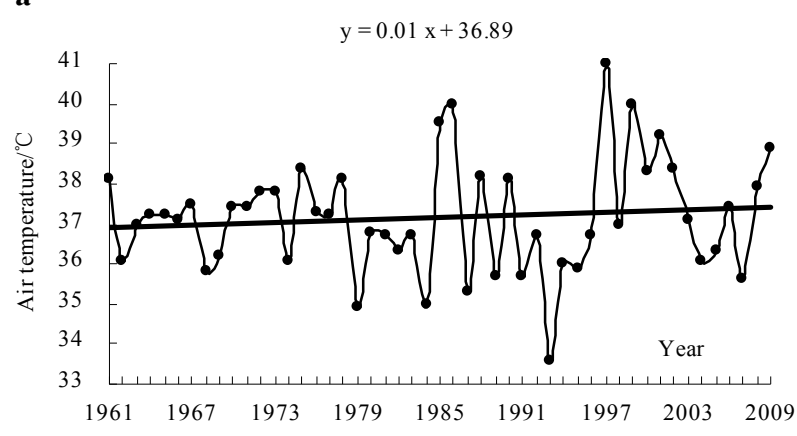

b

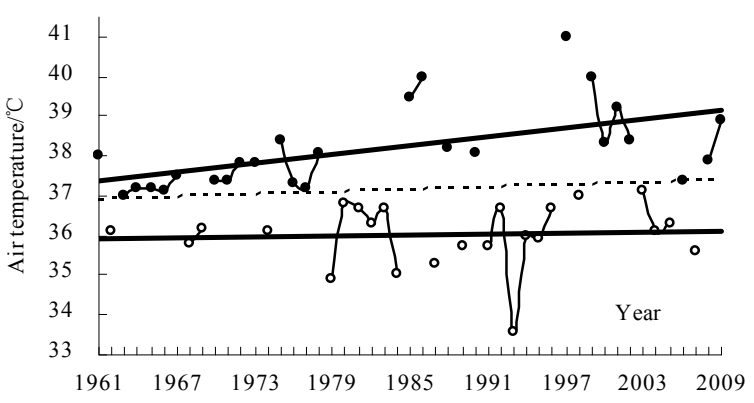

Figure 4. a) Variation of the maximum temperatures during 1961-2009; b) Increasing trend of the maximum temperatures during 1961-2009

\subsubsection{Minimum Temperature}

During 1961-2009, the annual minimum temperature in Minqin was $-24.99^{\circ} \mathrm{C}$ in average, with the lowest in 2008 (February 1st), $-32.2^{\circ} \mathrm{C}$. It showed a significant decreasing trend $(\mathrm{P}>0.05)$ (Figure 5a), at the rate of $-0.19^{\circ} \mathrm{C} \cdot(10 \mathrm{a})^{-1}$. The inter-annual difference of minimum temperature during 1961-2009 displayed an insignificant increasing trend $(\mathrm{P}>0.05)$ (Figure $5 \mathrm{~b}$ ). In Figure 5b, the values on the line above the general trend line display an insignificant decreasing trend $(\mathrm{P}>0.05)$; whereas those below the general trend line display a significant decreasing trend $(\mathrm{P}<0.05)$, with the decreasing rate of $-0.56^{\circ} \mathrm{C} \cdot(10 \mathrm{a})^{-1}$.

The inter-annual differences of the maximum and minimum temperatures during 1961-2009 were insignificant $(\mathrm{P}>0.05)$ (Figure 5c). 
$\mathbf{a}$

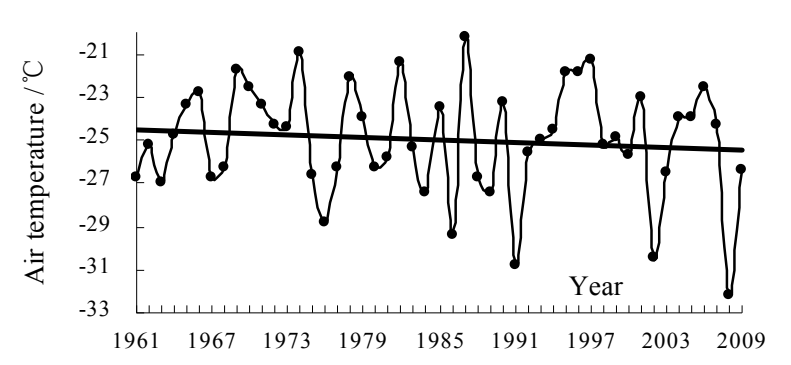

b

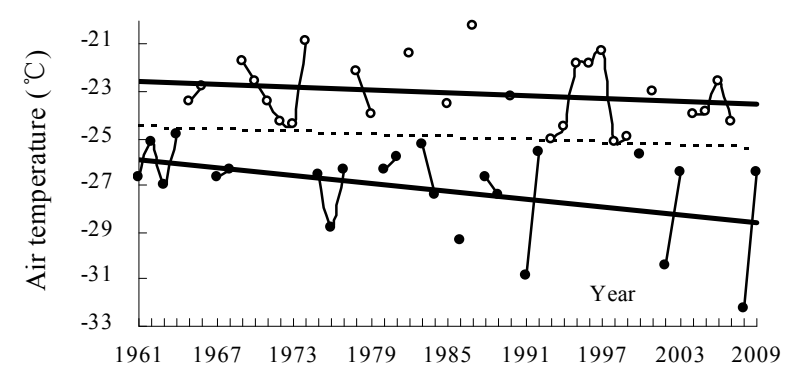

c

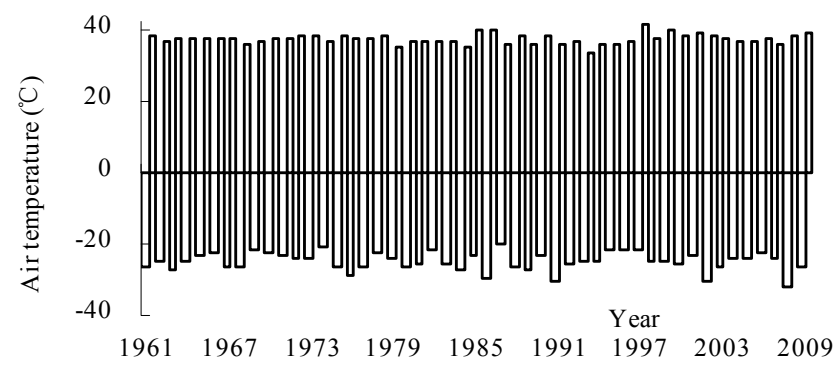

Figure 5. a) Variation of the minimum temperatures during 1961-2009; b) The increasing differences of the minimum temperatures during 1961-2009; c) The variation trend of the maximum and minimum temperatures during 1961-2009

\subsection{Precipitation}

\subsubsection{Annual Variation of Precipitation}

During 1961-2009, the annual maximum precipitation in Minqin was $185.8 \mathrm{~mm}$ (in 1973), and the minimum was 42.2mm (in 1962). The inter-annual variations of the annual precipitation during 1961-2009 showed an insignificant rising trend $(\mathrm{P}>0.05)$ (Figure 6a). In Figure 6a, the values correspondingly below the general trend line display a significant increasing trend $(\mathrm{P}<0.05)$ with a rate of $4.73 \mathrm{~mm} \cdot(10 \mathrm{a})^{-1}$; whereas those above the trend line display an insignificant increasing trend $(\mathrm{P}>0.05)$ with a rate of $1.00 \mathrm{~mm} \cdot(10 \mathrm{a})^{-1}$. The annual precipitation during 2000-2009 increased by 14.4mm, comparing with that during 1961-1999.

\subsubsection{Periodic Variation of Precipitation}

The running average of the precipitation during 1961-2009 showed that precipitation variation experienced eight stages: the increasing trend during 1961-1971, the decreasing trend during 1971-1976, the increasing trend during 1976-1981, the decreasing trend during 1981-1993, the increasing trend during 1993-1996, the decreasing then increasing trend during 1996-2001, the increasing trend during 2001-2004, and the decreasing then increasing trend during 2001-2009 (Figure 6b).

\subsubsection{Monthly Precipitation}

Since 1961, the maximum diurnal rainfall was $45.4 \mathrm{~mm}$ (June 12th, 1987). The precipitation mainly concentrated in August, July, September and June (73.73\% to the total in whole the year). The inter-annual precipitation differences in August, July, June, September and May were great. The changing trend of precipitation in different months was not significant (Figure 6c).

\subsubsection{Correlation between Precipitation and Temperature}

Analyses showed that during 1961-2009, the temperature in June was negatively significantly correlated to the annual precipitation $(\alpha<0.05)$, the temperature in November was positively significantly correlated to the annual precipitation $(\alpha<0.05)$ (Figure $6 \mathrm{~d}$ ), and the correlation between the temperatures in the remaining months/the mean annual temperature and the annual precipitation were insignificant. 
a
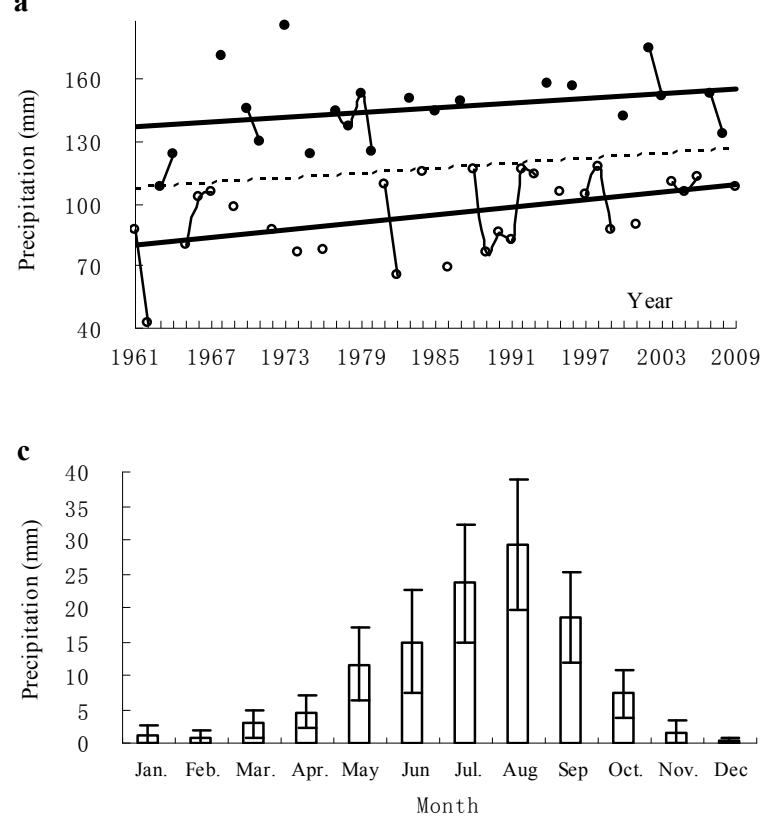

b

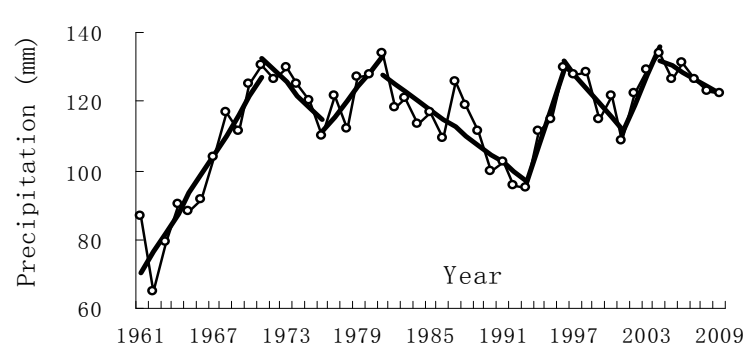

d

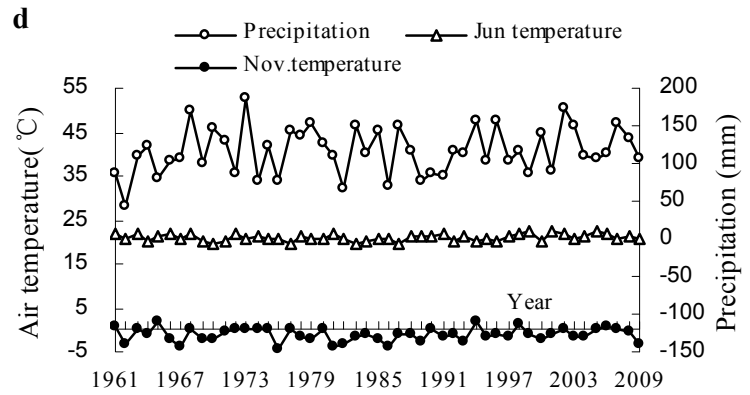

Figure 6. a) Variation of annual precipitation during 1961-2009; b) Periodic variation of the annual precipitation during 1961-2009; c) Monthly precipitation and the standard difference during 1961-2009; d) Significant correlation between the average temperatures in June/November and the annual precipitation

\subsection{Variation of Air Humidity}

\subsubsection{Periodic Variation of Air Humidity}

The maximum air humidity during $1961-2009$ was $57 \%$ (in 2006), and the minimum was $39 \%$ (in 1965). The inter-annual variations of the air humidity during 1961-2009 displayed a significant decreasing trend $(\mathrm{P}<0.05)$, with the rate of $-0.40 \% \cdot(10 a)^{-1}$ (Figure $7 a$ ).

During 1961-2009, the variation of air humidity experienced seven stages: the decreasing trend during 1961-1966, the increasing trend during 1966-1971, the decreasing trend during 1971-1976, the increasing trend during 1976-1992, the decreasing trend during 1992-2001, the increasing trend during 2001-2007, and the decreasing trend during 2007-2009 (Figure 7b).

\subsubsection{Monthly Air Humidity}

During 1961-2009, the air humidity in April was the minimum while that in December was the maximum. The monthly air humidity showed an increasing trend, with significant increasing $(\mathrm{P}<0.01)$ found in January, February, June, July, August, September and December, the less significant increasing found in March and October $(\mathrm{P}<0.05)$, and the insignificant increasing found in April, May and November $(\mathrm{P}>0.05)$ (Figure $7 \mathrm{c})$.

\subsubsection{Correlation between Air Humidity and Precipitation}

As mentioned above, the precipitation from 1961 to 2009 displayed an insignificant increasing trend, while the air humidity increased significantly. Analyses showed there was a significantly positive correlation between the variation of air humidity and the annual precipitation during this period $(\alpha<0.05)$ (Figure $7 \mathrm{c}$ ). The air humidity from January to October were positively significantly related to the precipitation in the corresponding months $(\alpha<0.01)$; and those in November and December were positively insignificantly related to the precipitation in the corresponding months $(\alpha<0.05)$ (Table 2$)$. 

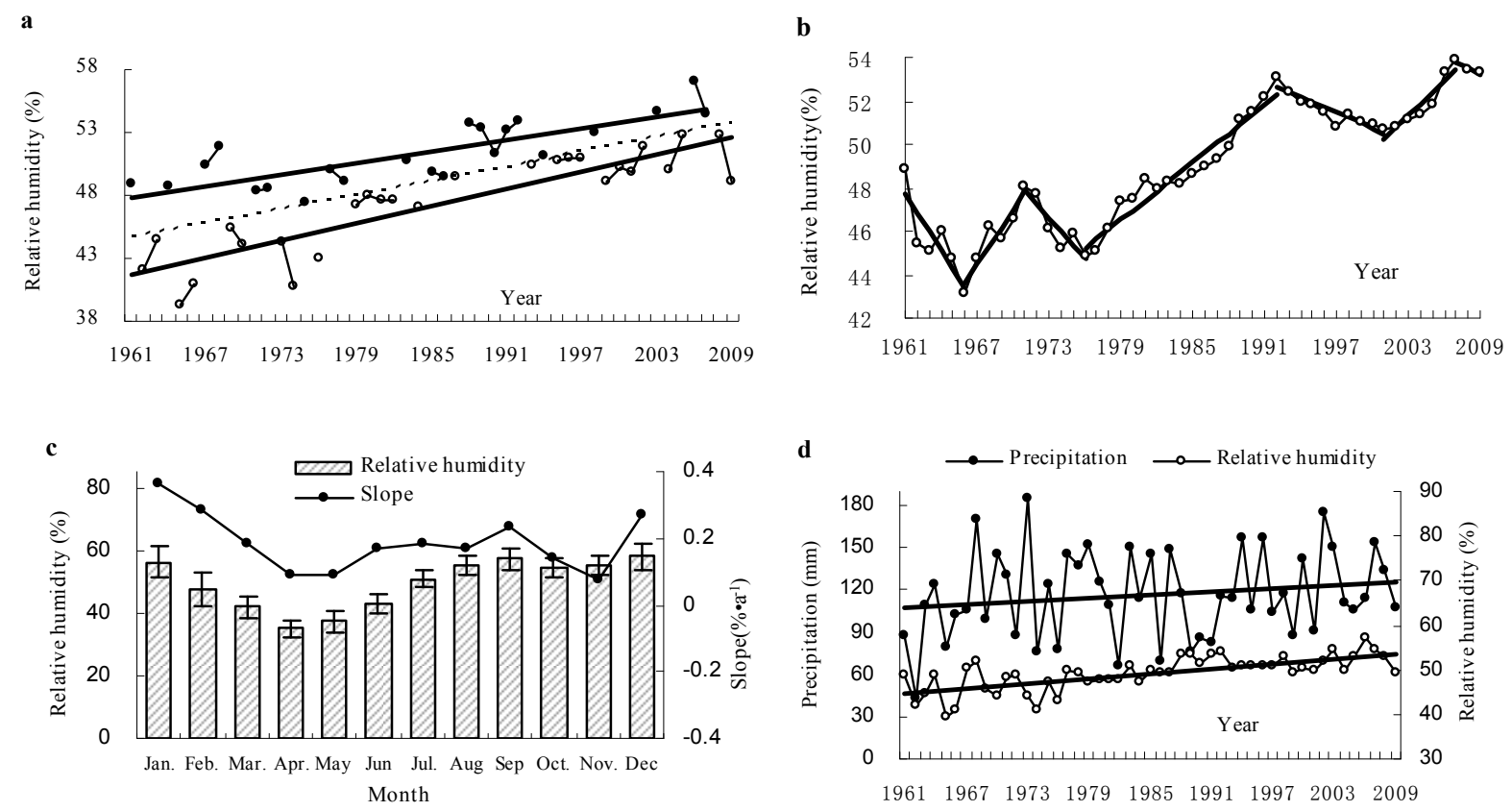

Figure 7. a) The inter-annual variation of air humidity during 1961-2009; b) Periodic variation of air humidity during 1961-2009; c) Monthly variation of air humidity during 1961-2009; d) The correlation between air humidity and the annual precipitation during 1961-2009

Table 2. Correlation between monthly air humidity and the precipitation during 1961-2009

\begin{tabular}{|c|c|c|c|c|c|c|c|c|c|c|c|c|}
\hline Months & Jan. & Feb. & Mar. & Apr. & May & Jun. & Jul. & Aug. & Sep. & Oct. & Nov. & Dec. \\
\hline Relat & $.471 * *$ & $0.413 * *$ & $0.579 * *$ & $0.582 * *$ & $0.783^{* *}$ & $0.728^{* *}$ & $0.559 * *$ & $0.442 * *$ & $0.632 * *$ & $0.458^{* *}$ & $0.345^{*}$ & .29 \\
\hline
\end{tabular}

Note: $* *$ denotes the significant correlation at the level of $\alpha<0.01$; denotes the significant correlation at the level of $\alpha<0.05$

\subsection{Variation of Sandstorms}

\subsubsection{Variation of the Seasonal Incidence of the First Sandstorm in a Year}

During 1988-2009, the incidence of the first sandstorm in a year advanced significantly (P<0.05) (Figure 8a). In Minqin, sandstorms appear most frequently in April, followed by in March and May. The seasonal distribution of the 136d sandstorms during 1988-2009 showed the peaks were extending to May and March, with a significant increasing rate in May $(\mathrm{p}<0.05)$ (Table 3).

Table 3. Variation of the sandstorm days in different months during 1988-2009

\begin{tabular}{|c|c|c|c|c|c|c|c|c|c|c|c|c|}
\hline Months & Jan. & Feb. & March & April & May & Jun & July & Aug. & Sep. & Oct. & Nov. & Dec. \\
\hline The average days(d) & 0.25 & 1.00 & 2.25 & 3.67 & 1.42 & 0.67 & 0.58 & 0.25 & 0.00 & 0.08 & 0.50 & 0.67 \\
\hline Slope & 0.00 & 0.04 & 0.10 & -0.22 & $0.20 * *$ & 0.05 & -0.05 & -0.04 & 0.00 & -0.02 & -0.04 & 0.01 \\
\hline
\end{tabular}

Note: $* *$ denotes the significant correlation at the level of $\alpha<0.01$

\subsubsection{Variation of the Sandstorm Intensity}

During 1988-2009, the average visibility during sandstorm event significantly decreased $(\mathrm{P}<0.05)($ Figure $8 \mathrm{a})$, which was an indicator of the increasing sandstorm intensity. However, the decreasing trend of the minimum visibility within a year was insignificant (Figure 8b). During 1988-2009, the decreasing trend of the average duration and the maximum duration of sandstorms were insignificant $(\mathrm{P}>0.05)$ (Figure $8 \mathrm{c})$. 


\subsubsection{Correlation between Sandstorm, Air Temperature and Air Humidity}

Analysis showed the incidence of the first sandstorm displayed an advancing trend. The correlation among the incidence month of the first sandstorm in a year, the average temperature in the previous month and the changing trend of the annual average temperature were insignificant $(\alpha>0.05)$. The average visibility during sandstorm events was negatively significantly related to the temperature in May $(\alpha<0.05)$, and was positively significantly related to the temperature in September $(\alpha<0.05)$. During 1998-2009, there were 136 days of sandstorms. The distribution of the sandstorms by month was negatively significantly related to the relative air humidity in the corresponding months $(\alpha<0.01)$ (Figure 8d). Accordingly, the increasing of the relative air humidity was one of the important factors contributing to the decreasing of sandstorms. Study carried out in Xinjiang Province supported this result (Hu et al., 2001).

a
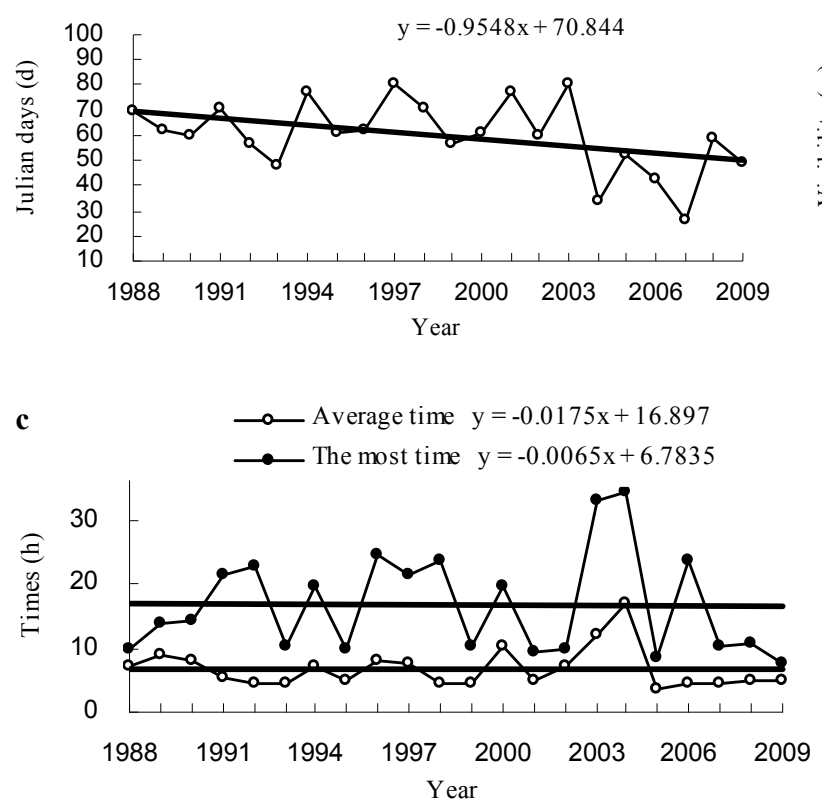

b

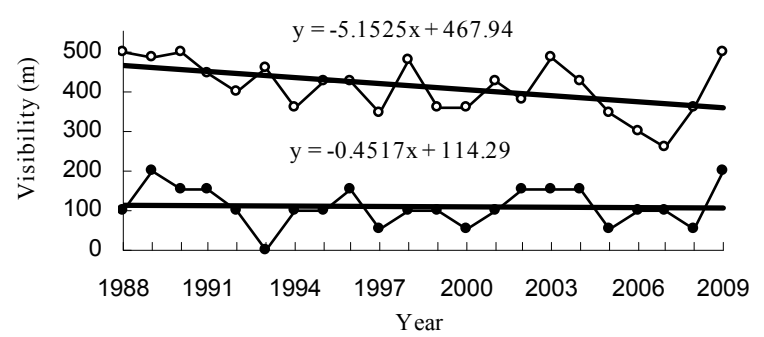

d

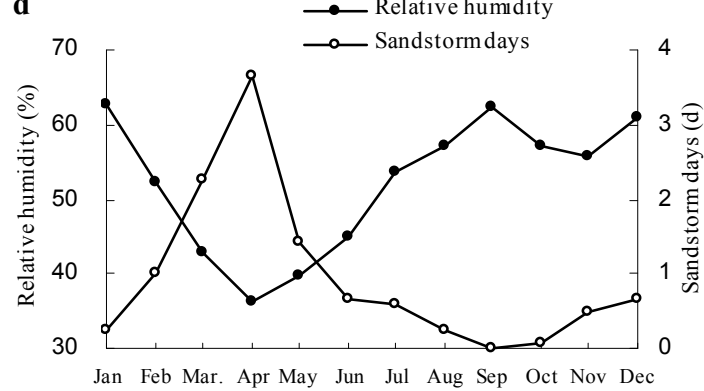

Figure 8. a) Variation of the starting dates of sandstorms during 1988-2009; b) Variation of the visibility in sandstorm events during 1988-2009; c) Variation of the annual sandstorm duration during 1988-2009;

d) Correlation between the sandstorm and air humidity during 1988-2009

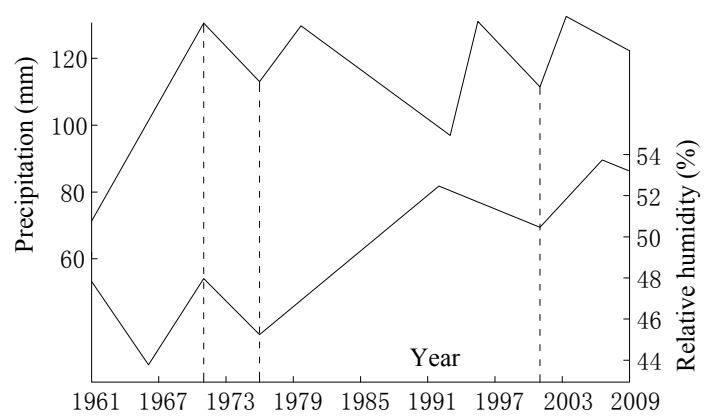

Figure 9. The variation phases of air humidity and precipitation during 1961-2009 were not completely corresponded

\section{Discussion}

As illustrated, there was a significant positive correlation between the annual precipitation and the annual air humidity during 1961-2009. The variation of the annual precipitation experienced 8 stages (Figure 6b) of the air humidity experienced 7 stages (Figure 7b). The annual precipitation and air humidity from 1971 to 1976 
displayed a decreasing trend, and those from 2001 to 2009 showed an increasing then decreasing trend. The variation in other stages were not completely corresponded (Figure 9). Therefore, the correlation between precipitation and air humidity can only be reflected from the overall variation trend in many years. Due to dry climate in the desert area, the rainfall will immediately get evaporated, so the short-term precipitation cannot impact the variation of air humidity.

Rainfall in desert is rare with great fluctuation. Therefore, the regression trend of precipitation increasing since 1961 was not significant. However, an increasing trend could be found from the annual average precipitation for many years. For example, the annual average precipitation during 2000-2009 increased by $25.9 \mathrm{~mm}$, in contrast to that during 1961-1969; and increased by $14.4 \mathrm{~mm}$, in contrast to that during 1961-1999. This result is consistent with the results from Japanese scholars (Kitoh et al., 1997) and Chinese scientists (Jin et al., 2005; Leng et al., 2007).

The temperatures in June and November in the study site showed an insignificant increasing trend (Table 1). The rainfall was mainly concentrated in August, July, September and June (the raining season) (Figure 6c). The temperature in June was negatively significantly correlated with the annual precipitation, which was likely one of the contributory factors to the low temperature in the raining season. The temperature in November was positively significantly correlated with the annual precipitation, which was possibly a coincidence.

The desert normally has low vegetation coverage, The specific heat of sands is $0.9 * 105 \mathrm{~J} \cdot\left(\mathrm{kg} \cdot{ }^{\circ} \mathrm{C}\right)^{-1}, 1 / 4.7$ of water's, $4.2 * 105 \mathrm{~J} \cdot\left(\mathrm{kg} \cdot{ }^{\circ} \mathrm{C}\right)^{-1}$. The heat conductivity coefficient of sand grains is $0.03 \mathrm{~W} \cdot(\mathrm{m} \cdot \mathrm{K})^{-1}, 1 / 19$ of water's, $0.58 \mathrm{~W} \cdot(\mathrm{m} \cdot \mathrm{K})^{-1}$. Therefore, the temperature of the sands rises more rapidly, which can reach over $70^{\circ} \mathrm{C}$ in summer (Chang \& Zhao, 2006). The exposed sandy land can reflect large amount of sun radiation into the near-ground atmosphere. So temperature rises rapidly in spring in the desert, which is the key reason why desert is so sensitive in responding to global warming.

Data analysis showed that in the study area during 1961-2009, there was rare rainfall in April (rainfall from January to April occupy $8.17 \%$ of the total in whole the year), whereas more rainfall in summer and autumn (rainfall from June to September occupy $73.88 \%$ of the total in whole the year). As mentioned above, the specific heat of water is relatively higher, which played a buffer function to the extreme temperatures. In spring, the air is dry and vegetation cover is low, which may contribute to the increased instability of the maximum temperature in the study area. Further study in this field is needed.

Sandstorms in the study site mainly appear in April, March and May (Table 3). The spring sandstorms in Xinjiang, Hexi corridor of Gansu and the west of Inner Mongolia are mainly brought by the cold airstream under the force of Siberian high pressure which extends southeasternly. The bigger the gradient between the cold airstream and the temperature in desert area is, the bigger the gradient of the air pressure will be; the bigger the gradient of the air pressure is, the higher the wind velocity, and the stronger the sandstorm intensity will be. This is the reason why the rising temperature in May is negatively correlated with the decreasing visibility during sandstorm event. The temperature in September showed an insignificant decreasing trend (Table 1), and the intra-annual average visibility displayed a significant decreasing trend. Therefore, they are positively significantly correlated with each other. The advance of sandstorm incidence is directly related to the advance of temperature rising in spring.

Global warming will induce the extinction of species (Qin, 2007)and the spread of he diseases (IPCC, 2007; Sun et al., 2002). The instable variations of maximum and minimum temperatures will threaten human being's health. However, the studies on the instability of climatic variation are scarce. In the desert area in northwest China, sand storms occur earlier than usual and the intensity became greater due to temperature rising in spring. The temperatures in March and April become more instable, which will led to yields reduction of fruits and crops (Chang et al., 2006), even more, the freezing harm to animals.

\section{Conclusion}

During 1961-2009, the rising rate of the annual average temperature in Minqin was $0.110^{\circ} \mathrm{C} \cdot(10 \mathrm{a})^{-1}$, which was higher than world's average reported in IPCC TAR and IPCC AR4, also higher than the figure in the report "the temperature in China rose by $0.4-0.5^{\circ} \mathrm{C}$ in recent 100 years", but lower than the rising rate of average temperature in northeastern China in the past 20 years.

The temperature rising in Minqin was most significant in February, followed by that in April. Spring was apparently warming in Minqin. In the global warming process, the temperature variations in winter and spring are getting more and more instable.

The inter-annual variation of maximum temperature was more significant, which indicated the instability of the 
maximum temperature. Both the variation trend of the minimum temperature and the increasing trend of variation differences in many years were not significant; the increasing trend of the differences between maximum and minimum temperatures was also insignificant.

The increasing trend of the inter-annual precipitation was not significant. There was a significant negative correlation between the temperature in June and the annual precipitation; whereas there was a significant positive correlation between the temperature in November and the annual precipitation. The annual air humidity increased and became evidently stable. The increasing trend of air humidity was significantly related to the increasing of annual precipitation.

Due to global warming, sandstorm advanced evidently, with significantly increased intensity (the average visibility decreased). There was a negative correlation between the decreased visibility and the temperature rising in May.

During 1961-2009, the variation of the annual mean temperature experienced 7 stages, of the annual precipitation experienced 8 stages, and of the annual air humidity experienced 7 stages. However, the phases of these variations were not completely corresponded.

\section{Acknowledgement}

This study is supported by the state "973" pre-project: Formation and ecological effects of the accumulated sand belt at the oasis fringe in Hexi region of Gansu province, northwestern China (2011CB411912).

\section{References}

Chang, Z. F., \& Zhao, M. (2006). Study on desert ecology in Minqin. Gansu Science and Technology Press, 30-64.

Ding, J. M., \& Yan, J. P. (2007). An analysis on characteristics of climate change in Shan-Gan-Ning region in recent 50 years. Journal of Arid Land Resources and Environment, 21(6), 124-129.

Ding, Y. H. (2002). Predict environmental changes in western China. Assessment of environmental evolution in western China. Beijing: Science Press, 1-231.

Houghton, J. T., Ding, Y. H., Griggs, D. J., Noguer, M., van der Linden, P. J., Dai, X., ... Johson, C. A. (2001). Contribution of working group I to the third assessment report of the intergovernmental panel on climate change. Cambridge, UK: Cambridge University Press, p881.

Hu, R. J., Fan, Z. L., Wang, Y. J., Yang, Q., \& Huang, Y. Y. (2001). Assessment on the impact of climate change on environment in Xinjiang since recent 50 Years. Arid Land Geography, 24(2), 97-103.

Hulme, M. (1996). Recent climatic change in the world's dry land. Geophysical Research Letters, 23(1), 61-64. http://dx.doi.org/10.1029/95GL03586

Hulme, M., Osborn, T. J., \& Johns, T. C. (1998). Precipitation sensitivity to global warming: Comparison of observations with Had CM 2 simulations. Geophysical Research Letters, 25(17), 3379-3382. http://dx.doi.org/10.1029/98GL02562

IPCC. (1990). The IPCC Scientific Assessment. Climate Change. Cambridge: Cambridge University Press, p137-164.

IPCC. (2007a). Impacts, adaptation and vulnerability contribution of working group II to the fourth assessment report of the intergovernmental panel on climate change. Cambridge, UK and New York, USA: Cambridge University Press (in press).

IPCC. (2007b). Summary for policy-makers of the synthesis report of the IPCC fourth assessment report. Cambridge, UK: Cambridge University Press (in Press).

Jin, L. Y., Fu, J. L., \& Chen, F. H. (2005). Spatial differences of precipitation over northwest China during the last 44 years and its response to global warming. Scientia Geographic Sinica, 25(5), 567-572.

Kitoh, A., Yukimoto, S., Noda, A., \& Motol, T. (1997). Simulated changes in the Asian summer monsoon at times of increased atmospheric $\mathrm{CO}_{2}$. Journal of the Meteorological Society of Japan, 75(6), 1019-1031.

Leng, Z. X., Ge, L. M., Haimid, Y., \& Narbay, Abdusallih. (2007). Changes of average air temperature and rainfall in Urumqi under background of global warming. Journal of Arid Land Resources and Environment, 21(4), 60-64.

Mann, M. E., Bradley, R. S., \& Hughes, M. K. (1999). Northern hemisphere temperature during the past millennium: Inferences, uncertainties and limitations. Geophysical Research Letters, 26(6), 759-762. 
http://dx.doi.org/10.1029/1999GL900070

Qin, D. H., Din, Y. H., Wang, S. W., Wang, S. M., Dong, G. R., Lin, E. D., ... Wu, G. H. (2002). Ecological and Environmental change in west China and its response strategy. Advances in Earth Sciences, 17(3), 314-319.

Qin, D. H., Luo, Y., Chen, Z. L., Ren, J. W., \& Shen, Y. P. (2007). Latest Advances in Climate Change Sciences: Interpretation of the synthesis report of the IPCC fourth assessment report. Advances in Climate Change Research, 3(6), 311-314.

Sha, W. Y., Shao, X. M., \& Huang, M. (2002). Climate warming and its impact on natural regional boundaries in China in the 1980s. Science in China (Series D), 32(4), 317-326.

Sun, C. Q., Gao, F., \& Qu, J. S. (2002). Latest know ledge on global climate change. Journal of Nature, 24, 114-122.

Wang, S. W., \& Dong, G. R. (2002). Environmental characteristics and its evolution in western China. Qin DH. Assessment of Environmental Evolution in Western China. Beijing: Science Press, pp1-242.

Zhai, P. M., Zhang, X. B., Wan, H., \& Pan, X. H. (2005). Trends in total precipitation and frequency of daily precipitation extremes over China. Climatic Change, 18(1), 1096-1108. 